\title{
AVALIAÇÃO DE CARACTERÍSTICAS BROMATOLÓGICAS DA FORRAGEM DE MILHO EM DIFERENTES DENSIDADES DE SEMEADURA E ESPAÇAMENTOS ENTRE LINHAS
}

\author{
Evaluation of bromatologic characteristics of corn forrage in differents \\ densities of sowing and row spacings
}

\author{
Cláudio Garcia Durán Alvarez ${ }^{1}$, Renzo Garcia Von Pinho², Iran Dias Borges ${ }^{3}$
}

\begin{abstract}
RESUMO
A grande utilização do milho Zea mays L. para a produção de forragem permitiu a maior intensificação da atividade pecuária. Além disso, por ter uma boa composição nutricional, possibilitou maiores ganhos na produção animal. O valor nutritivo do milho está diretamente relacionado ao arranjo de plantas, densidade de semeadura, espaçamento entre linhas e arquitetura da planta. Estes fatores podem interferir na composição nutricional da planta de milho. Em função disso, há uma tendência de redução no espaçamento e aumento na densidade de semeadura, privilegiando assim cultivares de arquitetura mais ereta. Buscou-se com este trabalho avaliar o comportamento de híbridos de milho de diferentes arquiteturas foliares, submetidos a dois espaçamentos entre linhas e duas densidades de plantas, em dois anos agrícolas. Foram conduzidos separadamente em cada ano dois experimentos, sendo que no primeiro adotouse o espaçamento de $0,70 \mathrm{~m}$ entre linhas, e no segundo experimento adotou-se $0,90 \mathrm{~m}$ entre linhas. $\mathrm{O}$ delineamento utilizado em cada experimento foi o de blocos casualizados em esquema de fatorial $3 \times 2$, para avaliar os desempenhos de três híbridos (AG1051 - híbrido duplo, AG 9010 - híbrido simples, DKB440 - híbrido tríplo) e duas densidades de semeadura (55.000 e 75.000 plantas ha-1). Os espaçamentos $\left(0,70 \mathrm{~m}\right.$ e 0,90 m) e as densidades (55.000 e 75.000 Plantas ha $^{-1}$ ) não influenciam os teores de proteína bruta, FDN e FDA. O teor de proteína bruta é influenciado apenas pelo fator anos. O valor da porcentagem de FDA varia em função das cultivares e do ano considerado. O híbrido AG1051 apresentou os maiores teores de FDN e FDA, conseqüentemente, é a cultivar mais fibrosa e menos digestível.
\end{abstract}

Termos para indexação: Zea mays, arranjo de plantas, proteína bruta, FDN, FDA.

\begin{abstract}
The great use of corn Zea mays L. for forage production enabled the greater intensification of animal raising. In addition, for having a good nutritional composition, it has enabled increased gain of animal production. However, the nutritive value of corn may be related directly to agronomical aspects of the plants. Aspects such as density, spacing and leaf canopy of hybrids can affect the nutrient composition of the forage. As related with that, there has been a trend in reducing the row spacing and increasing the densities of sowing, privileging more erect materials, as the simple hybrids, aiming at higher productivity and greater operational efficiency. The objective of this work was to investigate the behavior of corn hybrids of different leaf canopy submitted to two interrow spacings, in two densities of sowing, and to two years of cultivation. The design utilized in the experiments (row spacings of 0,7 or 0,9 meters) was that of randomized blocks in a 3x2 factorial scheme, with the performance of three hybrids (AG1051, AG 9010, DKB440) and two densities of sowing (55,000 and 75,000 plants.ha $\left.{ }^{-1}\right)$ being evaluated. The spacings $(0,70 \mathrm{~m} \mathrm{e} 0,90 \mathrm{~m})$ and densities of sowing $\left(55,000\right.$ e 75,000 plantas ha $\left.{ }^{-1}\right)$ had no influence over neither gross protein content nor over the NDF or ADF. The gross protein content is influenced only by the year factor. The AG1051 has presented the highest NDF and ADF contents, thus being the crude fibrous and less digestible material.
\end{abstract}

Index terms: Zea mays, Arrangement of plants, Crude Protein, NDF, ADF.

(Recebido para publicação em 29 de dezembro de 2004 e aprovado em 10 de outubro de 2005)

\section{INTRODUÇÃO}

O milho Zea mays L. é uma planta muito utilizada como forragem destinada à alimentação animal. Isso se deve a seu alto valor energético, sua boa composição de fibras, além de seu alto potencial de produção de MS aliado à produção de grãos que enriquece a forragem produzida. Contudo, a qualidade da forragem pode variar bastante em função do nível de tecnologia e do sistema de manejo utilizado no processo produtivo. Esta qualidade irá influenciar diretamente os ganhos de produção animal, daí a necessidade de se conhecer a composição da forragem utilizada. Em função disso, trabalhos de pesquisa enfocando alternativas de espaçamento entre linhas, densidade de plantas, adaptação de híbridos e eficiência no manejo da cultura têm recebido relevante atenção da comunidade científica.

'Zootecnista, M.Sc. Fitotecnia - Fundação Bahia - Av. Ahylon Macêdo, 11 - Barreiras, BA - 47.806-180 - claudioduran@bol.com.br 2Professor Adjunto do Departamento de Agricultura da Universidade Federal de Lavras/UFLA - Campus Universitário - Departamento de Agricultura/DAG Cx. P. 3037 - 37.200-000 -Lavras, MG - renzo@ufla.br 37.200-000.

${ }^{3}$ Engenheiro Agrônomo, D.Sc. Fitotecnia, Professor Adjunto do Departamento de Ciências Agrárias da Universidade Estadual de Montes Claros Campus Janaúba - Cx. P. 91 - 39440.000 - Janaúba, MG - iran.borges@unimontes.br 
A tendência atual é a redução do espaçamento entre linhas de plantas de milho, que promove distribuição mais eqüidistante das plantas na área, podendo aumentar a eficiência do uso da radiação fotossinteticamente ativa, água e nutrientes, incrementando a produtividade e a qualidade da forragem (LESKEM \& WERMKE, 1981; PAIVA, 1991).

Paiva (1991) observou que o espaçamento de 0,7 metros entre linhas, proporcionou maior teor de proteína bruta na planta de milho do que o espaçamento de $0,90 \mathrm{~m}$. Ninje \& Seth (1988) afirmam que a população de plantas tem efeito significativo sobre os teores de proteína bruta. Leskem \& Wermke (1981), usando altas populações de plantas, observaram que houve melhoria na qualidade da fibra bruta devido ao aumento de carboidratos solúveis no colmo. Segundo Almeida Filho (1996), Nussio \& Manzano (1999) e
Vasconcelos (2004), os teores médios de proteína bruta, FDN e FDA encontrados nas silagens de milho de planta inteira, são respectivamente $7-7,5 \% ; 50 \%$ e $30 \%$.

\section{MATERIAIS E MÉTODOS}

O trabalho foi realizado em área experimental do Departamento de Agricultura da UFLA, nos anos agrícolas de 2001/02 e 2002/03, no município de Lavras-MG, sob sistema de cultivo convencional, em um Latossolo vermelho-escuro de textura argilosa (Tabela 1). As análises bromatológicas foram realizadas no Laboratório de Análises Químicas do Departamento de Zootecnia da UFLA. As variações na temperatura média e na precipitação acumulada por decêndio, ocorridas durante a condução dos experimentos, são apresentadas nas Figuras 1a e 1b.

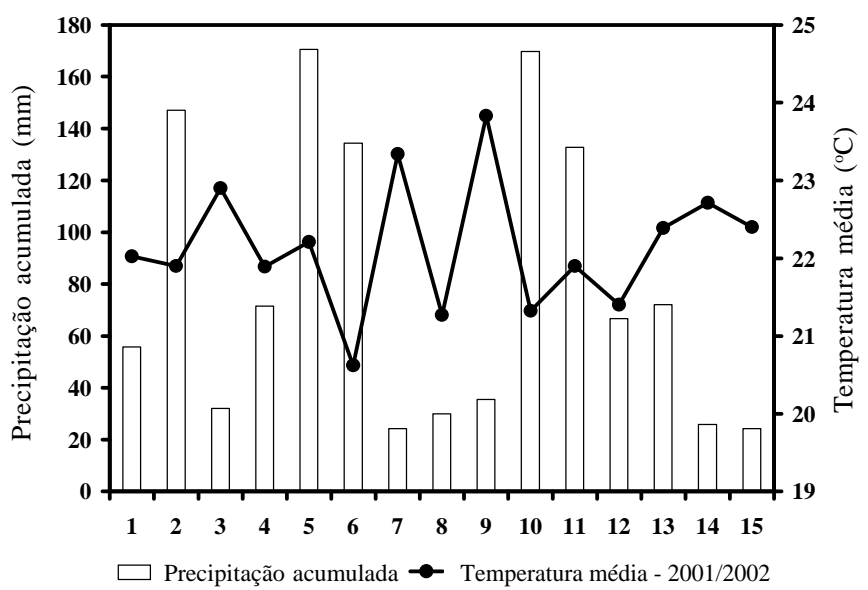

FIGURA 1a - Dados de precipitação acumulada e temperatura média por decêndio, de 01/11/2001 a 30/03/2002, em Lavras, MG. Dados obtidos no setor de Bioclimatologia da UFLA. Lavras - MG, 2004.

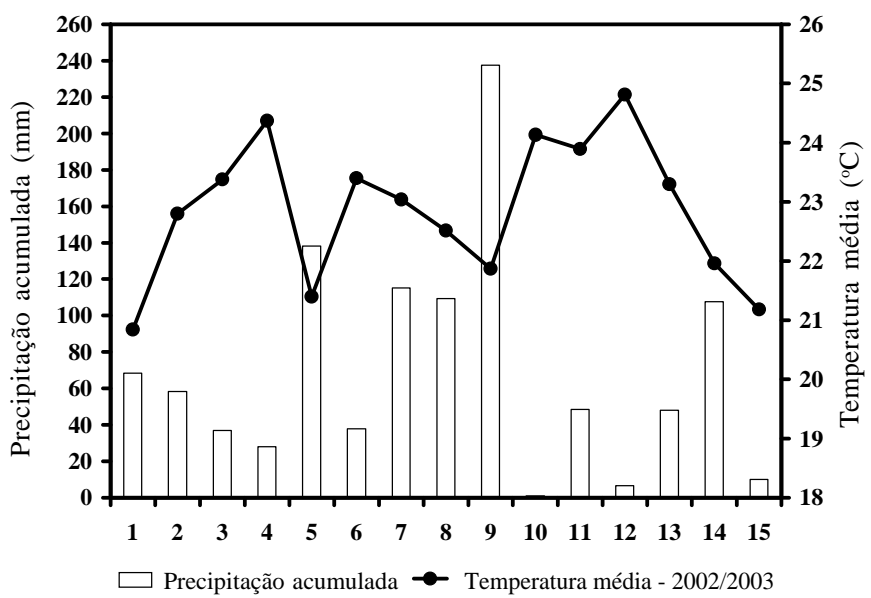

FIGURA 1b - Dados de precipitação acumulada e temperatura média por decêndio, de 01/11/2002 a 30/03/2003, em Lavras, MG. Dados obtidos no setor de Bioclimatologia da UFLA. Lavras - MG, 2004.

Ciênc. agrotec., Lavras, v. 30, n. 3, p. 409-414, maio/jun., 2006 
TABELA 1 - Resultados das análises de amostras de solo $(0-20 \mathrm{~cm}$ profundidade) da área onde foram conduzidos os experimentos. UFLA, Lavras - MG, 2004.

\begin{tabular}{lcc}
\hline Características & Unidade & Valores \\
\hline $\mathrm{pH}$ em água & $\mathrm{mg} / \mathrm{dm}^{3}$ & 5,4 \\
$\mathrm{P}$ (Fósforo Mehlich I) & $\mathrm{mg} / \mathrm{dm}^{3}$ & 20,6 \\
$\mathrm{~K}$ (Potássio Mehlich I) & $\mathrm{mg} / \mathrm{dm}^{3}$ & 70,0 \\
$\mathrm{Ca}$ (Cálcio) & $\mathrm{cmol}_{\mathrm{c}} / \mathrm{dm}^{3}$ & 3,0 \\
Mg (Magnésio) & $\mathrm{cmol}_{\mathrm{c}} / \mathrm{dm}^{3}$ & 1,0 \\
$\mathrm{SB}$ (Soma de Bases) & $\mathrm{cmol}_{\mathrm{c}} / \mathrm{dm}^{3}$ & 4,2 \\
$\mathrm{t}$ (CTC efetiva) & $\mathrm{cmol}_{\mathrm{c}} / \mathrm{dm}^{3}$ & 4,3 \\
T (CTC a ph 7,0) & $\mathrm{cmol}_{\mathrm{c}} / \mathrm{dm}^{3}$ & 7,8 \\
$\mathrm{~m}$ (saturação/alumínio) & $\%$ & 2,0 \\
V (saturação/bases) & $\%$ & 53,7 \\
Matéria Orgânica & $\mathrm{Dag} / \mathrm{Kg}^{2}$ & 2,4 \\
P-rem & $\mathrm{mg} / \mathrm{L}$ & 20,5 \\
Boro (Água quente) & $\mathrm{mg} / \mathrm{dm}^{3}$ & 0,2 \\
Zinco & $\mathrm{mg} / \mathrm{dm}^{3}$ & 4,7 \\
Manganês & $\mathrm{mg} / \mathrm{dm}^{3}$ & 8,8 \\
Sulfato & $\mathrm{mg} / \mathrm{dm}^{3}$ & 13,8 \\
Classe textural & - & Argilosa \\
\hline
\end{tabular}

Em cada ano agrícola foram instalados dois experimentos, um considerando o espaçamento de 0,70 metros entre linhas, e outro considerando o espaçamento de 0,90 metros entre linhas. Em cada experimento avaliouse três híbridos de milho (AG1051 - híbrido duplo, grão dentado; AG9010 - híbrido simples, grão duro; e DKB440 - híbrido triplo, grão semi duro), em duas densidades de plantas $\left(55.000 \mathrm{e} 75.000\right.$ plantas $\left.\mathrm{ha}^{-1}\right)$.

$\mathrm{O}$ delineamento foi o de blocos casualizados, com os tratamentos dispostos em esquema fatorial 3 (Cultivares) x 2 (Densidades), com quatro repetições. Cada parcela constou de seis linhas de seis metros, sendo as duas centrais consideradas como área útil.

Foram colhidas todas as plantas da área útil de cada parcela quando os grãos apresentavam-se com a linha de leite localizada entre metade e dois terços do grão; este material foi triturado e homogeneizado, e em seguida retirouse uma amostra de $300 \mathrm{~g}$, que foi seca em estufa de ventilação forçada a uma temperatura de $55^{\circ} \mathrm{C}$ até a obtenção de peso constante. Posteriormente, essa amostra foi moída em moinho tipo Willey, com peneira de $1 \mathrm{~mm}$, para a determinação da matéria seca a $105^{\circ} \mathrm{C}$ (AACC, 1976) e realização das análises bromatológicas. Todos os procedimentos das analises químicas, seguiram as metodologias descritas por Silva (1990).

Avaliou-se o teor de proteína bruta (PB), o teor de fibra em detergente neutro (FDN) e o teor de fibra em detergente ácido (FDA). Os resultados de cada experimento foram submetidos à análise de variância. Posteriormente, procedeuse uma análise conjunta envolvendo os dois espaçamentos em cada ano, e sequiencialmente uma outra análise conjunta considerando, os dois anos de experimentação e os dois espaçamentos. As médias foram agrupadas pelo teste de Scott-Knott, a 5\% de probabilidade.

\section{RESULTADOS E DISCUSSÃO}

\section{Proteína bruta (PB)}

Pela análise de variância conjunta envolvendo os dois anos, constata-se que esta característica sofreu 
influência apenas do fator anos. O coeficiente de variação do experimento (CV\%) foi de $12,48 \%$.

Em 2002/03, o teor de proteína obtido $(6,54 \%)$ foi significativamente superior ao obtido em 2001/2002 (5,89\%). As condições climáticas prevalecentes durante o período de condução dos experimentos nos dois anos, influenciaram a composição protéica dos híbridos. No segundo ano a distribuição e intensidade das chuvas ocorridas durante a condução do experimento foram adequadas para a cultura do milho. Entretanto, no primeiro ano (2001/2002) ocorreu um veranico no período compreendido entre o final de novembro a meados de janeiro.

É importante salientar que os teores de proteína bruta encontrados neste trabalho foram semelhantes aos encontrados por Almeida Filho (1996), Cruz (1998) e Vasconcelos (2004).

\section{Fibra em Detergente Neutro (FDN)}

A análise de variância conjunta envolvendo os dois anos constatou efeito significativo para cultivar e para as interações cultivares*densidades e densidades*anos. O espaçamento entre linhas não influenciou o teor de FDN. A precisão experimental avaliada pelo coeficiente de variação (CV\%) do experimento foi de $4,39 \%$.

A cultivar AG1051, na densidade de 55.000 plantas ha-1, obteve os maiores teores de FDN, seguido pela cultivar DKB440 e o AG9010, que não diferiram entre si. Na densidade de 75.000 plantas ha ${ }^{-1}$, os teores de FDN das cultivares não diferiram entre si (Tabela 2).

O aumento da densidade de plantas para 75.000 plantas ha- ${ }^{-1}$ proporcionou redução nos teores de FDN do híbrido AG1051, não influenciando os outros dois híbridos. Este comportamento pode ser atribuído à formação de um colmo mais fibroso, observado em baixas densidades de plantas. Segundo Leskem \& Wermke (1981), ocorre uma melhoria na qualidade de colmo, quanto ao teor de carboidratos solúveis, em altas densidades de plantas o que poderia reduzir o teor de FDN. Estes dados podem sugerir que para um mesmo híbrido, uma maior densidade de plantas pode resultar em plantas com colmos mais finos e tenros. Todavia, as altas densidades têm alta correlação com a redução do peso de espigas, o que poderia prejudicar a qualidade de silagem (BARBOSA, 1995).

Segundo Cruz (1998), teores elevados de FDN podem levar a redução no consumo de MS pelo animal, resultando em baixo desempenho da produção. Vale ressaltar que a FDN é uma característica que está diretamente relacionada à velocidade de passagem do alimento pelo trato digestivo, e quanto menor o nível de FDN, maior o consumo de MS. Da mesma forma, é importante salientar que o teor de FDN está diretamente relacionado a fatores como ciclo da cultivar, temperaturas noturnas, teor de carboidratos solúveis, entre outros.

Nos anos de 2001/02 não houve diferenças entre os teores de FDN nas duas densidades utilizadas. Porém, no segundo ano de experimentação, a densidade de 75.000 pl ha-1 proporcionou uma redução de $1,84 \%$ no teor de FDN, quando comparado com a densidade de 55.000 plantas (Tabela 3).

O teor de FDN não variou entre os dois anos de experimentação considerando as duas densidades de plantas, apesar de uma melhor distribuição de chuvas ocorrida no período de condução do experimento em 2002/ 2003.

TABELA 2 - Resultados médios dos teores de FDN (\%) das cultivares em função das densidades, considerando a média dos espaçamentos e dos dois anos de experimentação. UFLA, Lavras-MG, 2004.

\begin{tabular}{|c|c|c|c|}
\hline \multirow[b]{2}{*}{ Cultivares } & \multicolumn{2}{|c|}{ Densidades } & \multirow[b]{2}{*}{ Médias } \\
\hline & 55.000 plantas ha $^{-1}$ & 75.000 plantas ha $^{-1}$ & \\
\hline AG1051 & $58,47 \mathrm{bB}$ & $55,58 \mathrm{aA}$ & 57,03 \\
\hline AG9010 & $54,55 \mathrm{aA}$ & $55,79 \mathrm{aA}$ & 55,17 \\
\hline DKB440 & $55,55 \mathrm{aA}$ & $54,92 \mathrm{aA}$ & 55,23 \\
\hline Médias & $56,19 \mathrm{~A}$ & $55,43 \mathrm{~A}$ & - \\
\hline
\end{tabular}

Médias seguidas de letras minúsculas distintas na coluna, diferem entre si pelo teste de $\operatorname{Scott-Knott~}(\mathrm{P} \leq 0,05)$. Médias seguidas de letras maiúsculas distintasna linha, diferem entre si pelo teste de " $F$ " $(\mathrm{P} \leq 0,01)$.

Ciênc. agrotec., Lavras, v. 30, n. 3, p. 409-414, maio/jun., 2006 


\section{Fibra em Detergente Ácido (FDA)}

Pela análise de variância conjunta envolvendo os dois anos de experimentação e os dois espaçamentos entre linhas, constatou-se para essa característica, a influência dos fatores cultivares e anos. O coeficiente de variação do experimento (CV\%) foi de 6,44\%.

O híbrido duplo AG1051 obteve maior teor de FDA do que os demais híbridos, que não diferiram estatisticamente entre si (Tabela 4). Os teores de FDA encontrados neste trabalho são semelhantes aos observados por Fonseca (2000) e Vasconcelos (2004).

Segundo Cruz (1998), a FDA está relacionada com a digestibilidade da forragem, pois é ela que contém a maior proporção de lignina, que é a fração da fibra indigestível, indicando assim, a quantidade de fibra que não é digestível. Além disso, também é um indicador do valor energético do material, ou seja, quanto menor a FDA, maior será o valor energético da forragem.

Assim, como ocorreupara os teores de FDN, os teores de FDA não foram influenciados pelos fatores densidades e espaçamentos.

No segundo ano de experimentação (2002/03), a porcentagem de FDA foi superior em 1,45\% a obtida em 2001/2002 (Tabela 4). Este resultado foi oposto ao que se esperava, pois, em 2002/2003 a distribuição de chuvas foi adequada à obtenção de altas produtividades na cultura do milho, e em 2001/2002 ocorreu um veranico no período compreendido entre o final de novembro de 2001 e meados de janeiro de 2002. Ainda que elevados, os teores de FDA obtidos no ano 2002/2003 podem ser considerados aceitáveis, segundo Almeida Filho (1996), Melo et al. (1998) e Vasconcelos (2004).

TABELA 3 - Resultados médios dos teores de FDN (\%) nas duas densidades em função dos anos de cultivo, considerando a média das cultivares e dos dois espaçamentos. UFLA, Lavras-MG, 2004.

\begin{tabular}{lccc}
\hline & \multicolumn{3}{c}{ Anos } \\
\cline { 2 - 4 } Densidades & $\mathbf{2 0 0 1 / 0 2}$ & $\mathbf{2 0 0 2 / 0 3}$ & Média \\
\hline 55.000 plantas ha $^{-1}$ & $55,62 \mathrm{aA}$ & $56,77 \mathrm{bA}$ & 56,19 \\
75.000 plantas ha $^{-1}$ & $55,93 \mathrm{aA}$ & $54,93 \mathrm{aA}$ & 55,43 \\
\hline Média & $55,77 \mathrm{~A}$ & $55,85 \mathrm{~A}$ & - \\
\hline
\end{tabular}

Médias seguidas de letras minúsculas distintas na coluna e maiúsculas distintas na linha, diferem entre si pelo teste de "F" $(\mathrm{P} \leq 0,01)$.

TABELA 4 - Resultados médios dos teores de FDA (\%) das cultivares e dos anos de cultivo, considerando a média das densidades e dos dois espaçamentos. UFLA, Lavras-MG, 2004.

\begin{tabular}{lll}
\hline \multirow{3}{*}{ Cultivares } & & FDA (\%) \\
\cline { 2 - 3 } & AG1051 & $31,6 \mathrm{~b}$ \\
& AG9010 & $27,7 \mathrm{a}$ \\
& DKB440 & $27,3 \mathrm{a}$ \\
\hline \multirow{2}{*}{ Anos } & Média & 28,86 \\
\hline & $2001 / 2002$ & $27,70 \mathrm{~b}$ \\
& $2002 / 2003$ & $29,17 \mathrm{a}$ \\
\hline & Média & 28,44 \\
\hline
\end{tabular}

Médias seguidas de letras minúsculas distintasna coluna para efeito de cultivares e de anos, diferem entre si pelo teste de Scott-Knott $(\mathrm{P} \leq 0,05)$ e teste de "F" $(\mathrm{P} \leq 0,01)$. 


\section{CONCLUSÕES}

Os espaçamentos $(0,70 \mathrm{~m}$ e $0,90 \mathrm{~m})$ e as densidades (55.000 e 75.000 Plantas ha ${ }^{-1}$ ) não influenciaram os teores de proteína bruta, FDN e FDA.

O teor de proteína bruta é influenciado apenas pelo fator anos.

O valor da porcentagem de FDA varia em função das cultivares e do ano considerado.

O híbrido AG1051 apresentou maiores teores de FDN e FDA do que os híbridos AG 9010 e DKB 440.

\section{REFERÊNCIAS BIBLIOGRAFICAS}

ALMEIDA FILHO, S. L. Avaliação de cultivares de milho (Zea mays L.) para silagem. Viçosa: UFV, 1996. 53 p.

AMERICAN ASSOCIATION OF CEREAL CHEMISTS. Approved methods of the American Association of Cereal Chemists. 7. ed. Saint Paul, 1976. 256 p.

BARBOSA, J. A. Influência do espaçamento e arquitetura foliar no rendimento de grãos e outras características agronômicas do milho (Zea mays L.). 1995. 48 f. Dissertação (Mestrado em Agronomia) - Escola Superior de Agricultura de Luiz de Queiroz, Piracicaba, 1995.

CRUZ, J. C. Cultivares de milho para ensilagem. In: CONGRESSO NACIONAL DOS ESTUDANTES DE ZOOTECNIA, 1998, Viçosa, MG.Anais... Viçosa: UFV, 1998. p. 93-114.

FONSECA, A. H. Características químicas e agronômicas associadas a degradabilidade da silagem de milho. 2000. 93 p. Dissertação (Mestrado em Fitotecnia) - Universidade Federal de Lavras, Lavras, 2000.
LESKEM, Y.; WERMKE, M. Effect of plant density and removal of ears, on the quality of forage mayse in a temperature climate. Grass and Forage Science, Oxford, v. 36, n. 3, p. 147-153, Sept. 1981.

MELO, W. M. C.; PINHO, R. G. von; CARVALHO, M. L. M. Avaliação de cultivares de milho, para produção de silagem na Região de Lavras, MG. Ciência e Agrotecnologia, Lavras, 1998. No prelo.

NINJE, P. M.; SETH, J. Effect of nitrogen on growth yield and quality of winter maize. Indian Journal Agonomy, New Delhi, v. 33, n. 1, p. 209-211, June 1988.

NUSSIO, L. G.; MANZANO, R. P. Silagem de milho. In: SIMPÓSIO SOBRE NUTRIÇÃO DE BOVINOS: ALIMENTAÇÃO SUPLEMENTAR, 7., 1999, Piracicaba. Anais... Piracicaba: FEALQ, 1999. p. 27-46.

PAIVA, L. E. Influência de níveis de nitrogênio, espaçamento e densidade no rendimento forrageiro e qualidade da silagem de milho (Zea mays $L$.). 1991. 82 f. Dissertação (Mestrado em Agronomia) Escola Superior de Agricultura de Lavras, Lavras, 1991.

SILVA, D. J. da. Análise de alimentos: métodos químicos e biológicos. 2. ed. Viçosa: UFV, 1990. 165 p.

VASCONCELOS, R. C. de. Resposta de milho e sorgo para silagem a diferentes alturas de corte e datas de semeadura. 2004. 124 p. Tese (Doutorado em Fitotecnia) - Universidade Federal de Lavras, Lavras, 2004. 